\title{
Effect of Occlusal Reduction on Post-Operative Pain in Patients with Irreversible Pulpitis and Symptomatic Apical Periodontitis Treated in a Single-Visit: A Randomized Clinical Trial
}

\section{Fadwa Sheesh*, Siza Zaghary and Marwa Bedier}

Department of Endodontics, Faculty of Dentistry-Cairo University, Egypt

*Corresponding Author: Fadwa Sheesh, Department of Endodontics, Faculty of

Dentistry- Cairo University, Egypt.
Received: March 02, 2020

Published: March 19, 2020

(C) All rights are reserved by Fadwa Sheesh., et al.

\section{Abstract}

Introduction: The purpose of this study was to evaluate the effect of occlusal reduction on post-operative pain.

Methods: Fifty-two patients diagnosed with symptomatic irreversible pulpitis and apical periodontitis in maxillary and mandibular molars were included in this study. The root canals were instrumented and obturated in a single-visit root canal treatment. The patients were randomly divided into 2 groups of 26 each. In Group A, the occlusal surface was reduced, whereas in Group B, the occlusal surface was not modified (no occlusal reduction). Each patient was asked to record his/her postoperative pain on a numerical rating scale (NRS) pre-operatively and at 6,12, 24, 48-hrs post-operatively.

Results: Showed similarity between the two groups regarding demographic data and pre-operative pain, as for Pain intensity, there was observable decrease at 6,12,24, till it disappeared at 48-hrs with no significant difference between both groups (P > 0.05).

Conclusions: Intact occlusal surface and reduced occlusal surface showed more or less similar effect on the post-operative pain in patients with symptomatic irreversible pulpitis and apical periodontitis performed in a single-visit.

Keywords: Apical Periodontitis; Occlusal Reduction; Post-Operative Pain; Single-Visit; Symptomatic Irreversible Pulpitis

\section{Introduction}

Pain is an unpleasant sensory and emotional experience associated with actual or potential tissue damage. It is the primary reason that dental patients seek endodontic therapy [1]. Post-operative pain after nonsurgical root canal treatment has been reported to range from approximately $3 \%$ to more than $50 \%$ [2]. Several factors have been attributed for post-operative pain such as; chemical factors including the extrusion of intra-canal medications, or irrigants [3], mechanical factors, including over instrumentation or extrusion of root-filling materials [4], or microbial injuries to the peri-apical tissues that result in acute inflammation [5].

Different methods have been used for managing post-operative pain and discomfort following root canal procedures, such as pre- operative analgesics, corticosteroid prescription, administration of long-acting anesthesia, and occlusal reduction [6], as reported that occlusal adjustment decreases the mechanical stimulation of sensitized nociceptors [7].

The value of occlusal reduction in preventing pain after endodontic instrumentation has been a source of controversy [6]. It was hypothesized that there may be certain pre-operative conditions that indicate the need of occlusal reduction in endodontically treated patients, such as the presence of irreversible pulpitis, presence of pre-operative pain, percussion sensitivity, peri-radicular radiolucency, swelling and history of bruxism [8], which creates a dilemma for dentists regarding whether they should reduce occlusal contacts to prevent pain after root canal treatment or not [7]. 
Several studies had evaluated the effect of occlusal reduction on post-operative pain and discomfort after root canal treatment in multiple-visits, while few evaluated the effect of occlusal reduction on post-operative pain after a single-visit root canal treatment which has not been sufficiently studied in literature, and within the scope of the present systematic search, to date, limited clinical trials in literature have been done to evaluate the effect of occlusal reduction on post-operative pain after a single-visit root canal treatment in patients with irreversible pulpitis and symptomatic apical periodontitis. The null hypothesis was that there is no significant difference in the post-operative pain between intact occlusal surface and reduced occlusal surface after a single-visit root canal treatment

\section{Subjects and Methods}

\section{Trial design and sample size calculation}

The trial design was a blinded, controlled, parallel grouped prospective randomized clinical trial and registered on www.clinicaltrials.gov with the identifier: NCT03189771. The trial was done following the guidelines in the declaration of Helsinki and approved by the Research Ethics Committee, Faculty of Dentistry, Cairo University with identifier: NCT03189771. All patients were asked to sign a printed informed consent to participate in the study after the explanation of the treatment procedures.

The primary outcome used for this power analysis was the effect of occlusal reduction on post- operative pain. Based upon the results obtained from Arslan., et al. [9], the effect size (d) was 11.6, using alpha $(\alpha)$ level of $0.05(5 \%)$ and Beta $(\beta)$ level of $0.20(20 \%)$ i.e. power $=80 \%$; the minimum estimated sample size was a total of 48 subjects ( 24 subjects per group). To compensate for a dropout rate of $10 \%$, the number was increased to a total of 52 subjects ( 26 subjects per group). Sample size calculation was performed using $\mathrm{G}^{*}$ Power Version 3.1.9.2.

\section{Participants selection}

Outpatients of the clinic of Endodontics, Faculty of Dentistry, Cairo University, Egypt, were diagnosed and checked for the eligibility criteria through careful medical history, dental history, clinical examination, in addition to proper intra-oral radiographic assessment.

Patients enrolled in the study diagnosed clinically and confirmed by pulp sensitivity tests as maxillary and mandibular molars with symptomatic irreversible pulpitis and apical periodontitis, show- ing normal peri-apical radiographic appearance or slight widening in the periodontal membrane space. Only patients between 20 and 50 years old were included in this study. Exclusion criteria were: Patients who had received antibiotic or analgesic treatment during the last 12 hours or who had any systemic disease, teeth with mobility, pocket depth greater than $5 \mathrm{~mm}$, teeth having no occlusal contacts, or teeth with periapical swelling or sinus tract.

\section{Randomization}

The random sequence was done using block randomization by (www.random.org) by a colleague and the random sequence table was kept with him. After eligibility assessment, the operator called the colleague for eligibility checking and to know the group assignment for the patients. Fifty-two outpatients from the clinic of Endodontics at the Faculty of Dentistry, Cairo University, Egypt were recruited to participate in the study, and were randomly assigned into two equal groups $(\mathrm{n}=26)$.

\section{Blinding}

Participants, outcome assessor and data analyst were blinded in this trial. The operator couldn't be blinded due to the nature of the study as the occlusal reduction done after finishing root canal treatment.

\section{Interventions}

\section{Clinical procedures}

Patients were asked to mark his/her level of pain on the preoperative Numerical Rating Scale (NRS) in the pain diary. Topical anesthesia was applied at the site of injection, then each patient was anaesthetized by inferior alveolar nerve block for mandibular molars or buccal infiltration for maxillary molars using a side loading aspirating syringe and 27-guage long needle (C-K ject, 27 gauge Long Disposable Dental Needles. Ultra Sharp, Tri-Bevel Point, Color-Coded Plastic Hub, Korea) with $1.8 \mathrm{ml}$ of $2 \%$ Mepivicaine $\mathrm{HCl}$ with 1:100,000 epinephrine local anesthetic solution (Carpule Mepecaine-L, Alexandria Company for Pharmaceuticals and Chemical Industries, Egypt).

Ten to fifteen minutes post-injection, the patient was asked if there was lip numbness as a subjective sign of IANB success, if not, the patient was given second anesthetic carpule. Once the lip numbness occurred, access cavity was done and teeth were isolated with a rubber dam.

Working length was determined using an electronic apex locator (Root ZX II, J.Morita USA, Irvine, C.A), which was confirmed 
with an intraoral peri-apical radiograph to 0.5 - 1 mm shorter than the radiographic apex. Root canals were mechanically prepared by crown down technique using Revo-S nickel titanium rotary instruments (Revo-S, MICRO-MEGA, France) at speed of $300 \mathrm{rpm}$ and torque of $1.8 \mathrm{~N} . \mathrm{cm}$. Buccal canals in maxillary molars and mesial canals in mandibular molars were prepared till size AS30 (size 30 /taper 0.06), while the palatal canal in maxillary molars and the distal single canal in the mandibular molars were prepared till size AS 40 (size 40/ taper 0.06).

During instrumentation, the root canals were irrigated with 5 $\mathrm{ml}$ of $2.6 \% \mathrm{NaOCl}$ by using a 30-gauge side-vented needle (Navi Tip, Ultradent South Jordan, UT, USA), placed within $2 \mathrm{~mm}$ from the working length between each successive instruments. After completion of the instrumentation, radiograph was taken to ensure proper master cone length, then the root canals were obturated by Revo-S Gutta-Percha points (Revo-S guta percha, MICRO-MEGA, France) by modified single cone technique using ADSEAL (ADSEAL, META BIOMDED CO., LTD, Korea.) and then the access cavity was sealed with Cavit (Cavit temoporary filling 3M ESPE, Germany.).

In Group A, all the occlusal contacts on the functional and nonfunctional cusps as well as on the marginal ridges were reduced using a diamond stone mounted in a high-speed hand-piece with copious coolant, then absence of any contact was checked by using the articulating paper, while in Group B, all the occlusal contacts on the functional and non-functional cusps as well as on the marginal ridges were left intact without any reduction, then Patients were asked to complete a NRS pain score at $6,12,24$, and 48-hrs postoperatively.

\section{Statistical analysis}

Numerical data was described as mean and standard deviation or median and range. Categorical data will be described as numbers and percentages. Data was checked for normality using Kolmogrov-Smirnov test and Shapiro-Wilk test. Comparisons between the two groups was done using the Student's t-test for normally distributed numeric variables, while Mann- Whitney test was used to compare between two groups for non-normally distributed numeric values.

Qualitative data including gender, age, arch distribution, tooth type, number of roots and number of canals were compared between the groups using the chi-square test. The significance level was set at $\mathrm{P} \leq 0.05$. Statistical analysis was performed with IBM (IBM Corporation, NY, USA) SPSS (SPSS, Inc., an IBM Company) Statistics Version 21 for Windows.

\section{Results}

The subject flow in this trial was illustrated in a COSORT flow diagram (Figure 1 and Table 1).

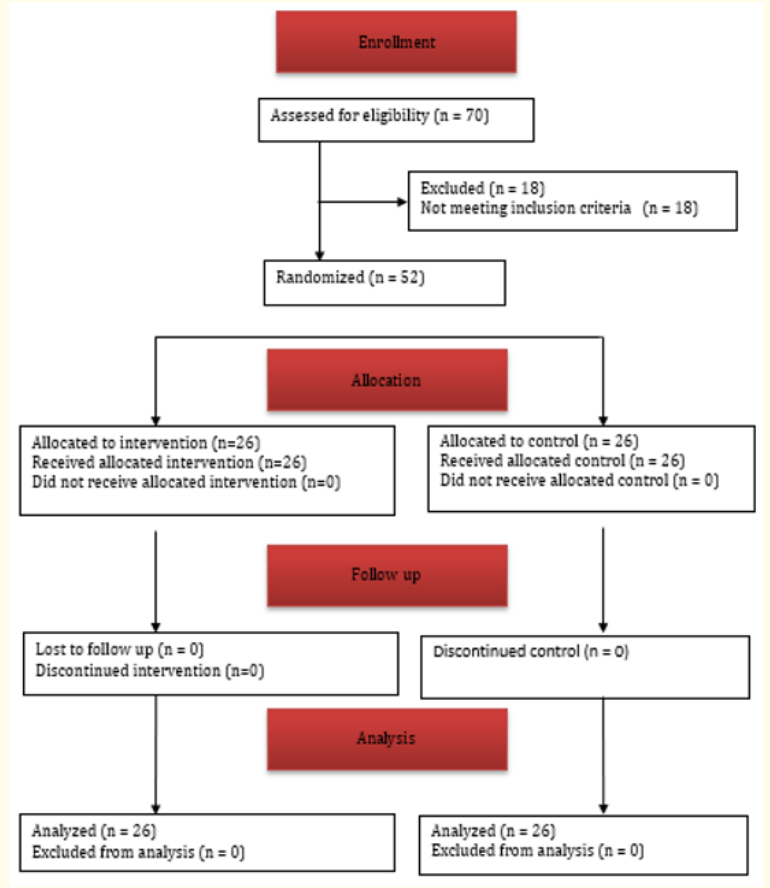

Figure 1: CONSORT 2010 flow diagram.

\begin{tabular}{|c|c|c|c|}
\hline & $\begin{array}{l}\text { Group A } \\
(\mathrm{n}=26)\end{array}$ & $\begin{array}{l}\text { Group B } \\
(n=26)\end{array}$ & $p$-value \\
\hline \multicolumn{4}{|l|}{ Age (Years) } \\
\hline Median & 35 & 30.5 & \\
\hline Range & $20-50$ & $21-45$ & 0.488 \\
\hline \multicolumn{4}{|l|}{ Gender } \\
\hline Male $[\mathrm{n}(\%)]$ & $7(26.9 \%)$ & $10(38.5 \%)$ & 0.375 \\
\hline Female $[\mathrm{n}(\%)]$ & $19(73.1 \%)$ & $16(61.5 \%)$ & \\
\hline \multicolumn{4}{|c|}{ Arch type distribution } \\
\hline Maxillary [n(\%)] & $10(38.5 \%)$ & $10(38.5 \%)$ & 1.000 \\
\hline Mandibular [n\%)] & $16(61.5 \%)$ & $16(61.5 \%)$ & \\
\hline \multicolumn{4}{|c|}{ Tooth type distribution } \\
\hline $1^{\text {st }}$ molar $[\mathrm{n}(\%)]$ & $16(61.5 \%)$ & $16(61.5 \%)$ & 1.000 \\
\hline $2^{\text {nd }} \operatorname{molar}[\mathrm{n}(\%)]$ & $10(38.5 \%)$ & $10(38.5 \%)$ & \\
\hline \multicolumn{4}{|c|}{ Number of roots distribution } \\
\hline 2 roots $[\mathrm{n}(\%)]$ & $13(50.0 \%)$ & $13(50.0 \%)$ & \\
\hline 3 roots $[\mathrm{n}(\%)]$ & $13(50.0 \%)$ & $13(50.0 \%)$ & 1.000 \\
\hline \multicolumn{4}{|c|}{ Number of canals distribution } \\
\hline 2 canals $[\mathrm{n}(\%)]$ & $3(11.5 \%)$ & $0(0 \%)$ & \\
\hline 3 canals $[\mathrm{n}(\%)]$ & $13(50.0 \%)$ & $16(61.5 \%)$ & 0.191 \\
\hline 4 canals $[\mathrm{n}(\%)]$ & $10(38.5 \%)$ & $10(38.5 \%)$ & \\
\hline \multicolumn{4}{|l|}{ Pre-operative Pain } \\
\hline Moderate & $2(7.7 \%)$ & $7(26.9 \%)$ & \\
\hline Severe & $24(92.3 \%)$ & $19(73.1 \%)$ & 0.067 \\
\hline None & $3(11.5 \%)$ & $2(7.7 \%)$ & \\
\hline
\end{tabular}

Table 1 
There was no statistically significant difference between the two groups concerning age, gender, arch type, tooth type, number of roots distribution, and number of canals.

The Mann-Whitney U test showed that there was no statistically significant difference between the pain intensity in the two groups at $6,12,24$, and 48-hrs post-operatively as shown in (Figure 2 and Table 2).

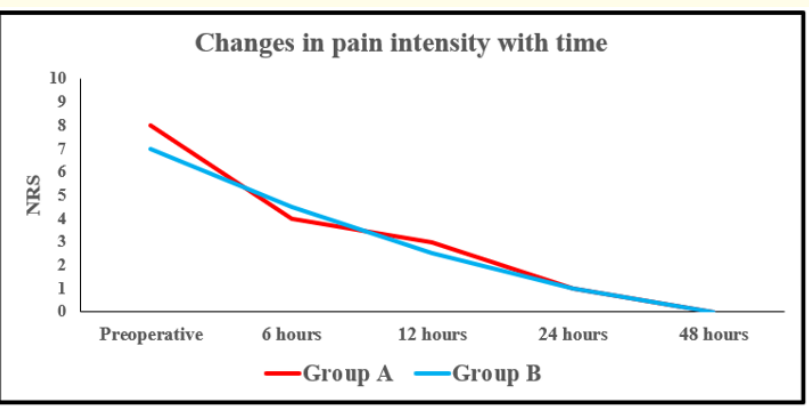

Figure 2

\begin{tabular}{|l|c|c|c|c|c|c|c|}
\hline & \multicolumn{3}{|c|}{ Group A } & \multicolumn{3}{c|}{ Group B } & \\
\hline & $\begin{array}{c}\text { Me- } \\
\text { dian }\end{array}$ & Min & Max & Median & Min & Max & $\begin{array}{c}\boldsymbol{p}- \\
\text { Value }\end{array}$ \\
\hline $\begin{array}{l}\text { Pre- } \\
\text { operative } \\
\text { pain }\end{array}$ & 8 & 6 & 10 & 7 & 6 & 10 & 0.259 \\
\hline At 6-hrs & 4 & 0 & 6 & 4.5 & 0 & 8 & 0.157 \\
\hline At 12-hrs & 3 & 0 & 5 & 2.5 & 0 & 6 & 0.970 \\
\hline At 24-hrs & 1 & 0 & 4 & 1 & 0 & 6 & 0.279 \\
\hline At 48-hrs & 0 & 0 & 3 & 0 & 0 & 4 & 0.922 \\
\hline
\end{tabular}

Table 2

Results of wilcoxon signed rank test for comparison between different points of NRS scores for Group A

- $\quad$ There was a decrease in NRS scores at 6, 12, 24, and 48hrs post-operatively compared to the pre-operative NRS scores; the decrease was statistically significant. $(\mathrm{p}<$ 0.0001).

- $\quad$ There was a decrease in NRS scores at $12,24,48$-hrs post-operatively compared to 6-hrs NRS scores, the decrease was statistically significant. $(\mathrm{p}<0.0001)$.
- There was a decrease in NRS scores at 24, 48-hrs post-operatively compared to 12-hrs NRS scores, the decrease was statistically significant. $(\mathrm{p}<0.0001)$.

- $\quad$ There was a decrease in NRS scores at 48-hrs post-operatively compared to 24-hrs NRS scores, the decrease was statistically significant. $(\mathrm{p}<0.0001)$.

Results of Wilcoxon signed rank test for comparison between different points of NRS scores for Group B

- $\quad$ There was a decrease in NRS scores at 6,12, 24, and 48-hrs post-operatively compared to pre-operative NRS score; the decrease was statistically significant $(p<0.0001)$.

- There was a decrease in NRS scores at $12,24,48$-hrs postoperatively compared to 6-hrs NRS scores, the decrease was statistically significant. $(\mathrm{p}<0.0001)$.

- There was a decrease in NRS scores at 24, 48-hrs postoperatively compared to 12-hrs NRS scores, the decrease was statistically significant. $(\mathrm{p}<0.0001)$.

- There was a decrease in NRS scores at 48-hrs post-operatively compared to 24-hrs NRS scores, the decrease was statistically significant. $(\mathrm{p}<0.0001)$.

\section{Discussion}

One of the most important aspects of endodontic practice is to control pain during and after root canal treatment [8]. Several studies have been performed to assess pain prevalence after root canal treatment. [10-11] The present study was designed as a doubleblind, parallel design, randomized clinical trial (RCT), which is a prospective, experimental study using primary data generated in the clinical environment. Individuals, similar at the beginning, are randomly allocated to two treatment groups and the outcome of the groups were compared after sufficient follow-up time. It is one of the strongest evidence of the clinical efficacy of preventive and therapeutic procedures in the clinical setting, which provide an unbiased estimate of the treatment effect.

Teeth with irreversible pulpitis and symptomatic apical periodontitis were selected to be included in the present study as postoperative pain occur frequently, even if the treatment is performed properly [12] and this was according to Parirokh., et al. (2013) [6], Asghar., et al. (2014) [13], Raza., et al. (2016) [14], Zeidan (2016) [15]. 
Maxillary and mandibular molars were selected according to Rosenberg., et al. (1998) [16] and Parirokh., et al. [2013] [6]. As it was found that molar teeth were significantly more susceptible to post-obturation pain $[5,17,18]$. It may be hypothesized that the complex root canal morphology of molar teeth, especially in the apical part and the higher number of root canals are more difficult to completely debride and usually associated with more post- obturation complications [19].

In this study, root canal treatment was completed in a singlevisit as Creech., et al. [1984] [20], Arslan., et al. [2017] [9], Wong., et al. [2015] [21] and Patil., et al. [2016] [22] concluded that there is no significant difference in the post- operative pain after done in single or multiple-visit root canal tratment. Single-visit root canal treatment has become a common practice and offers several advantages over multiple-visit, including reducing the need of additional anesthesia, the gingival trauma from rubber dam, and the risk of inter-appointment leakage through the temporary restorations [23-25]. Moreover, single-visit root canal therapy is less time consuming, more economically and, as a consequence, more appropriate to the needs of busy patients [26].

A numerical rating scale (NRS) was used for measuring postoperative pain intensity, and this was in accordance with Nekoofar., et al. [27] due to it's simplicity, with a limited number of choices ( 0 to 10), sound methodologic, easy to administrate, more sensitive than the visual rating scale (VRS) and less complicated than the visual analogue scale [28].

Zeidan [2016], [15] Parirokh., et al. [6] Arslan., et al. [2016], [9] and Raza., et al. [14] showed no effect of the patients' age, gender, and tooth type on the post-operative pain, while Zaman., et al. [2016], [29] Asghar., et al. [2014] [13] reported that age, gender, and tooth type are factors that influence the post- operative pain, thus as the result of the present study, showed a similar distribution of age, gender, arch type, tooth type, number of roots, number of canals and the pre-operative pain in both groups, then these factors were considered to be homogenous in both groups.

The primary outcome in this study was the post-operative pain at 6, 12, 24, 48-hrs, where Ali., et al. [2012] [30] reported that postoperative was more frequent in the first 24-hrs of the observation period after root canal treatment then quickly decreased, and that the overall incidence of post-operative pain decreased drastically after 48-hrs.
The occlusal reduction group and no-occlusal reduction group showed an observable drop in pain levels compared to the preoperative pain until disappeared, this was in accordance to Ali., et al. [2012] [30] who reported that the incidence of post-operative pain after root canal treatment decreased drastically after 48-hrs and Zeidan [2016] [15] who reported that pain levels started to decrease immediatly after root canal treatment till 48-hrs post- operatively, while the results was in contrast with Raza., et al [2016] [14] who reported that pain levels decreased after 24-hrs drastically in both groups.

Results showed no difference between the occlusal reduction group and the non-occlusal reduction group, in the post-operative pain, which was in agreement with Creech., et al. [1984], [20] Jostes, Holland [1984], [31] Parirokh., et al. [2013], [6] Asghar., et al. [2014], [13] Arslan., et al. [2015], [9] Zeidan [2016], [15] and Raza., et al. [2016], [14] while the results was in contrast with Rosenberg., et al [1998], [16] Sheikh., et al. [2015], [7] and Zaman., et al. [2016] [29] who reported that occlusal reduction has a significant effect on reducing post-operative pain, this variability in the results may be attributed to the difference in the inclusion criteria, methodology or the clinical procedures performed.

In conclusion, results of this study showed that occlusal reduction has no effect in reducing post-operative pain in patients with irreversible pulpitis and symptomatic apical periodontitis after single-visit root canal treatment compared to non-occlusal reduction.

\section{Bibliography}

1. Watkins CA., et al. "Anticipated and experienced pain associated with endodontic therapy". Journal of the American Dental Association 133 (2002): 45-54.

2. DiRenzo A., et al. "Post-operative pain after 1- and 2- visit root canal therapy". Oral Surgery, Oral Medicine, Oral Pathology, Oral Radiology 93 (2002): 605-610.

3. Gondim E., et al. "Postoperative Pain after the Application of Two Different Irrigation Devices in a Prospective Randomized Clinical Trial”. Journal of Endodontics 36 (2010): 1295-1301.

4. Harrison JW., et al. "Incidence of pain associated with clinical factors during and after root canal therapy. Part 2. Postobturation pain". Journal of Endodontics 9 (1983): 434-438.

5. Genet JM., et al. "Preoperative and operative factors associated with pain after the first endodontic visit". International Endodontic Journal 20 (1987): 53-64.

Citation: Fadwa Sheesh., et al. "Effect of Occlusal Reduction on Post-Operative Pain in Patients with Irreversible Pulpitis and Symptomatic Apical Periodontitis Treated in a Single-Visit: A Randomized Clinical Trial". Acta Scientific Dental Sciences 4.4 (2020): 85-91. 
6. Parirokh M., et al. "Effect of occlusal reduction on postoperative pain in teeth with irreversible pulpitis and mild tenderness to percussion". Journal of Endodontics 39 (2013): 1-5.

7. Sheikh H., et al. "Comparison of Post Instrumentation Pain in Teeth During Root Canal Treatment with or Without Occlusal Reduction". Pakistan Oral Dental Journal 35 (2015): 699-701.

8. Rosenberg PA. "Clinical strategies for managing endodontic pain”. Endodontic Topics 3 (2002): 78-92.

9. Arslan H., et al. "The effect of various occlusal reduction levels on postoperative pain in teeth with symptomatic apical periodontitis using computerized analysis: a prospective, randomized, double-blind study". Clinical Oral Investigations 21 (2017): 857-863.

10. An JX., et al. "Quantitative Evaluation of Pain with Pain Index Extracted from Electroencephalogram". Chinese Medical Journal 130 (2017): 3-8.

11. Kanaa MD., et al. "A prospective randomized trial of different supplementary local anesthetic techniques after failure of inferior alveolar nerve block in patients with irreversible pulpitis in mandibular teeth". Journal of Endodontics 38 (2012): 421-425.

12. Rehman K., et al. "Post-Endodontic Pain: Cases of Symptomatic Irreversible Pulpitis and Periapical Periodontitis: A Randomised Control Clinical Trial". Journal of Khyber College of Dentistry 3 (2012): 1.

13. Ashgar S., et al. "Occlusal Reduction Reduces Postoperative Pain After Endodontic Instrumentation". Pakistan Oral and Dental Journal 34 (2014): 539-542.

14. Raza I., et al. "Effect of Occlusal Reduction on Frequency of Post Operative Pain Relief Following an Endodontic Intrumentaion". Pakistan Oral and Dental Journal 36 (2016): 6-9.

15. Zeidan BM. "Evaluation the Effect of Occlusal Reduction on Postoperative Pain in Teeth with Irreversible Pulpitis and Mild Tenderness to Percussion". Rafidain Journal of University 38 (2016): 128-140.

16. Rosenberg PA., et al. "The effect of occlusal reduction on pain after endodontic instrumentation". Journal of Endodontics 24 (1998): 492-496.

17. O'Keefe EM. "Pain in endodontic therapy: preliminary study". Journal of Endodontics 2 (1976): 315-319.
18. Yesilsoy C., et al. "Post-endodontic obturation pain: A comparative evaluation". Quintessence International 19 (1988): 431438.

19. Ng Y., et al. "Prevalence of and factors affecting post-obturation pain in patients undergoing root canal treatment". International Endodontic Journal 37 (2004): 381-391.

20. Creech JL., et al. "Effect of occlusal relief on endodontic pain". Journal of the American Dental Association 109 (1984): 64-67.

21. Wong AW., et al. "Treatment outcomes of single-visit versus multiple-visit non-surgical endodontic therapy: a randomised clinical trial". BMC Oral Health 15 (2015): 1-11.

22. Patil AA., et al. "Incidence of postoperative pain after single visit and two visit root canal therapy: A randomized controlled trial". Journal of Clinical and Diagnostic Research 10 (2016): ZC09-ZC12.

23. Vera J., et al. "One- versus two-visit endodontic treatment of teeth with apical periodontitis: A histobacteriologic study". Journal of Endodontics 38 (2012): 1040-1052.

24. Albashaireh ZS and Alnegrish AS. "Postobturation pain after single and multiple-visit endodontic therapy". Journal of Dentistry 26 (1998): 227-232.

25. Walton FR. "Endodontic interappointment flareups: a prospective study of incidence and related factors". Journal of Endodontics 18 (1992): 172-177.

26. Cohen S., et al. "Pathways of the Pulp". $11^{\text {th }}$ edition. Mosby Elsevier (2016).

27. Nekoofar MH., et al. "Comparison of the Effect of Root Canal Preparation by Using WaveOne and ProTaper on Postoperative Pain". Journal of Endodontics 41 (2015): 575-578.

28. Wu SJ and Julliard K. "Children's preference of benzocaine gel versus the lidicaine patch". Pediatric Dentistry 25 (2003): 401405.

29. Zaman H and Shahnawaz Ahmed S. "Effect of Occlusal Reduction on Post Instrumentation Pain in Patients with Acute Irreversible Pulpitis". Pakistan Oral and Dental Journal 36 (2016): 119-121.

30. Ali S., et al. "Prevalence of and factors affecting post-obturation pain following single visit root canal treatment in Indian population: A prospective, randomized clinical trial". Contemporary Clinical Dentistry 3 (2012): 459. 
31. Jostes JL and Holland GR. "The effect of occlusal reduction after canal preparation on patient".

\section{Assets from publication with us}

- Prompt Acknowledgement after receiving the article

- Thorough Double blinded peer review

- Rapid Publication

- Issue of Publication Certificate

- High visibility of your Published work

Website: www.actascientific.com/

Submit Article: www.actascientific.com/submission.php

Email us: editor@actascientific.com

Contact us: +919182824667 